\title{
Critical thinking as room for subjectification in Education for Sustainable Development
}

Helen Hasslöf and Claes Malmberg

\begin{abstract}
Issues of sustainability are complex and often steeped with ethical and political questions without predefined or general answers. This paper deals with how secondary and upper secondary teachers discuss these complex issues, by analysing their aims for Education for Sustainable Development (ESD). With inspiration from discourse theory, their articulations about students as political subjects are analysed. Critical thinking emerged as a nodal point in teachers' discussions. In this study critical thinking is articulated as having various qualitative meanings related to different epistemological views. On one hand, critical thinking is articulated to invite room for subjectification; but on the other hand, room for subjectification is challenged when critical thinking is articulated through the educational aims of qualification and socialisation. A consequence of changing epistemological view might be that political and ethical issues take a back seat.
\end{abstract}

Keywords: education for sustainable development, environmental education, critical thinking, subjectification, functions of education

\section{Introduction and background}

Questions of sustainability pose challenges to education. What does this perspective mean when considering the purpose of education? The relationship between knowledge, politics and ethics is complex and sensitive, and one might ask how education should deal with questions imbedded in political and ethical interpretations. Should ESD work as an integrated aim of education, and what happens when it does?

These questions, which have been asked for several decades, have been recently accentuated through the UN Decade of ESD (Jickling 2003; Scott and Gough 2003; Stevenson 2007; Jickling and Walls 2008). These are important questions to consider, because when we ask why we educate and for what purpose we keep the democratic part of education alive (Biesta 2009a).

Among educational content for sustainable development, we find issues surrounding climate change, the use of natural resources, justice, human rights and democracy. It allows for the students' competence to act in the future and the vision of action competence (i.e., the vision of developing reflecting individuals with an awareness of conflicting interests). A broad and interdisciplinary obligation, Scott and Gough (2003) frame sustainability and learning as an issue of complexity, uncertainty, risk and necessity.

The initiative and mission of the United Nations Decade of Education for Sustainable Development (2004-2014) can be found on the website of UNESCO (UNESCO 2012, www.unesco.org): 
The overall goal of the UN Decade of Education for Sustainable Development (DESD) is to integrate the principles, values and practices of sustainable development into all aspects of education and learning. This educational effort will encourage changes in behaviour that will create a more sustainable future in terms of environmental integrity, economic viability and a just society for present and future generations.

In an educational context, this top-down perspective of promoting behavioural change in value-driven questions has been considered challenging and is vulnerable to claims that it amounts to indoctrination (Jickling 2003; Jickling and Wals 2008; Læssøe 2010) - that is, the promotion of a sustainable world served by experts or the worldview of the particular teacher in charge. The policy documents (e.g. UNESCO, 2006) also articulate the need for harmonious relations between the sustainability goals of social-cultural, economic, and environmental interests to envision sustainable development - a challenge given the conflicts of interest that arise when one faces the realities of our daily lives. The complexity of a mutual 'harmonisation' of such embedded diversity of values is difficult to envision, especially in light of a goal to fulfil a better future for all. Nevertheless, decisions that mutually affect those interests are an everyday concern.

In this complexity, we examine Swedish teachers' commitment to ESD. To approach ESD as a neutral learning of facts and skills may be as problematic as avoiding ESD for fear of indoctrination. It is interesting to reflect on how the qualification and socialisation of ESD works in relation to an individual's political and ethical development.

Our interest in this study is to gain knowledge from social practice; in particular, how teachers discuss ESD. Of particular interest is if and how teachers discuss the way that education or learning situations could leave room for students to develop as political subjects. We use the term political in line with Mouffe's (2000) definition: 'the dimension of antagonism that is inherent in human relations' (Mouffe 2000, 15; Lundegård and Wickman 2012). According to Mouffe, there is no universal or rational best argument in political disputes, only different ethico-political interpretations.

In this, we approach Biesta's function of subjectification (2009a) as a process of education that emphasises the individual's mutual relationship with the world on a personal level in relation to structural and general perspectives. Biesta (2009b) emphasises the function of subjectification as an indispensable part of education and raises the question of what education is for as an important part of why we educate.

If we regard issues of sustainability also as questions of exploratory art (i.e., questioning how we live our lives and other ethical and political issues that do not have any predefined or general answers) the subjectification process is crucial.

If we discuss the purpose of education, through the three functions of education as: qualification, socialisation and subjectification; these give possibilities for the reflection and analysis of education and its aims. The three functions mutually affect each other in education, but when we discuss the purpose of education (i.e., what makes up a good education) it is important to distinguish between these three functions. Is it especially important to be aware of the distinction between the function of subjectification on one hand, and qualification and socialisation on the other (Biesta 2009a). 
We consider Biesta's theoretical outline of the three functions of education as a fruitful tool to problematise which aims we prioritise in teaching and educationIn this study, we will primarily use purpose (or aim), which we relate to Biesta's functions. We want to clarify that the context in which we use purpose is in relation to the teacher's articulations of purpose in the situated practice they are part of and not as an intention.

We present a theoretical outline wherein we elaborate on Biesta's (2009a) functions of education to clarify our approach of the functions as an analytical lens. This is followed by a methodological section and then an analysis of the teachers' discussion about what constitutes 'good' ESD.

\section{Three functions of education}

The function of qualification refers to how knowledge, skills and understanding allow students to 'do something'. It also refers to education's contribution to development and growth, as well as for political and cultural literacy. Through its socialising function, education situates individuals into existing ways of doing and being. Socialisation serves to introduce newcomers into particular social practices and to become part of existing social orders. In other words, socialisation works to transmit particular norms and values as the continuation of culture and tradition.

Subjectification, on the other hand, has to do with the uniqueness of humans. It is a way to express agency and 'independence' to the orders of a community. In this way, the function of subjectification can be understood as a counterbalance to socialisation (Biesta 2010). Even so, subjectification is a relational concept and focuses on an awareness of an individual's uniqueness rather than the group's collective identity. If we only focus on the democratic order and dismiss the establishment's politics and maintenance of that order, we miss an important aspect of democratic politics (Laclau and Mouffe 2001). It could be seen as a process that allows students the possibilities to develop a more independent approach to education, wherein they have the possibility to be addressed as a subject of responsibility for others in their own uniqueness as human beings. This is something other than being a representative of a predefined order, with, for example, inherent human values. Subjectification focuses on the personal, responsible actions within a situation - a situation to learn from (without a predefined right answer) rather than to learn for. In this way, it also differs from, for example, identity, which Biesta refers to as more as a question of identification by someone and/or identification with something, as in a third person perspective (Winter 2011). We argue that ESD not only has the purposes of qualification and socialisation, but also ought to leave room for subjectification. To emphasise this and make it functional as an analytical lens, we will use the expression room for subjectification.

\section{Room for subjectification}

Subjectification is not about learning predefined content or competence. It is a matter of arranging education in a way that gives space to challenge existing orders, to get new perspectives on an issue and to leave possibilities for the students to explore their own relation to existing discourses. We argue that the process of subjectification is something 
that teaching situations could create room for even though it never can be expected as an outcome. Hence, we use the phrase room for subjectification.

\section{From ESD policy to the curriculum and teachers' articulations}

Environmental education has been part of school education for several decades in large parts of the world with a growing focus on sustainability, emphasised through the Decade of Education for Sustainable Development (Scott and Gough 2003; Rudsberg and Öhman 2010). It has been a journey for a 'good future', with an emphasis on education for change (Wals 2009). This has resulted in the formulation of the goals of education in international policy documents as well as in national and local curriculums. It has engaged national school boards, teachers' everyday teaching and informal education (Leo and Wickenberg 2013).

The formulation from the National Agency of Education in Sweden (2013) is an example of how goals from international policy (i.e., UNESCO) of environmental perspectives are implemented into the national curriculum of education. The formulation conforms to the international policy declarations of ESD:

Environmental perspectives in education should provide students with insights so that they can not only contribute to preventing harmful environmental effects, but also develop a personal approach to overarching, global environmental issues. Education should illuminate how the functions of society and our ways of living and working can best be adapted to create sustainable development. (National Agency for Education; Curriculum for the Upper Secondary School 2013, p 6)

The paragraph states that education 'should' illuminate how students best 'adapt' to create sustainable development in their ways of living and working. This normative perspective indicates an existing predefined answer of how to act 'to create sustainable development'. Furthermore, the qualification ought to provide knowledge that could give the students insight on how 'to prevent harmful environmental effects'. On the other hand, the formulation also puts forward the importance of encouraging students to 'develop a personal approach' to global environmental issues.

In line with this quote, environmental perspectives in education should provide insight into how to prevent harmful environmental effects, illuminate ways of how one's living and working is best adapted to create conditions for sustainable development and leave room for students to develop their personal positions to global environmental issues. In other words, qualification and socialisation is seen to deliver the right environmentally friendly answers, while at the same time, a personal position is highlighted (subjectification) as an ability to question what was just presented as desirable. How is this 'personal position' conceivable? What room is there for student's personal position in relation to the socialisation and qualification goals of education for sustainable development?

To be able to problematise this further, we use examples from social practices where, in discussions with colleagues, teachers develop what they deem important in ESD. From this situated practice we discuss how these articulations create meaning in relation to what makes up the purpose and function of education. Our method of analysing this process of 
meaning-making borrows tools from discourse theory. To focus this issue we formulate the following research question:

- How is students' ability to develop as political subjects articulated when teachers discuss what they see as important in ESD?

\section{Methodology \\ Setting the scene}

We wanted to create possibilities for teachers to discuss what is important when teaching ESD. Thus, we created groups of teachers who are colleagues to discuss ESD (with three to six teachers in each group). Five groups were arranged during autumn 2012, with a total of twenty teachers involved (with three to six teachers in each group).

The participants were science and social science teachers in secondary and upper secondary schools. The schools were selected on the basis that they were working on projects with sustainability themes or were certified ESD schools. The deciding factors for which schools were selected consisted of schools with practical opportunities to manage the arrangements and if the teachers showed interest for this type of discussion with their colleagues. The schools chosen are all located in southern Sweden.

Each group discussion (five in total) lasting approximately one hour was recorded and transcribed. The discussion was initiated with a question from the researcher (the first author of this study) asking what the teachers regard as important when teaching ESD and if they might have missed some processes of importance during their latest period /project of ESD. During the discussion, comments and questions were posed from the researcher to clarify statements or ask questions to bring the discussion back to its original theme. The transcripts of these discussions constitute the empirical basis of our analyses.

\section{Tools from discourse theory}

To study teachers' meaning-making of ESD, we apply an approach of discourse theory which takes inspiration from Laclau and Mouffe (2001). It us to analyse how discourses emerge and develop; how the complex struggle of possible interpretative prerogatives and reformulating processes work to articulate definitions and make meaning in the actual context. Since we are interested in analysing how teachers approach ESD - with different educational aims - we find this approach fruitful for our purpose.

We are aware of Laclau and Mouffe's wider societal and political focus and interest in theory development. However, we try to adapt their framework to our perspective and narrow the focus to illuminate the social practice of teachers' reciprocal discussions. We pay attention to the teachers' utterances as different voices in a dialogic meaning-making and analyse how different ESD discourses may be articulated. Our focus is on the teachers' articulations regarding students' possibilities to develop as political subjects in the teaching process of ESD. 


\section{Articulation of discourses}

We use the concept of discourse in two ways. First, as an analytical concept. The framing of discourses can be seen as analytical operations and something researchers construct. However, discourse is also used as something delimited in reality, with possibilities to unveil (Jørgensen and Phillips 2000). We consider social practices (e.g. ESD) as discourses constructed by ongoing articulation, giving meaning to the social context they are part of. Language use is therefore central for the analyses; as language use is a dynamic situated practice, discourses are continuously reconstructed. The struggle between and within discourses is in focus (i.e., how the articulations develop to find conclusive meanings and to 'close' the discourse in relation to other discourses). Nevertheless, a closed discourse should be seen only as temporarily closed and always in a dynamic articulation due to the particular context. On the other hand, even if everything seems to be in a constant struggle to be articulated between different discourses, Laclau and Mouffe refer to the social practices as partly structured, hence discourses could be hard to deconstruct. The point of departure is that discourses always could be reconstructed by new articulations, even if they do not have to be deconstructed. Discourses that have been articulated in the same way for a long time become invisible and, by this, they turn into 'objective' discourses which are hard to contest.

We regard language use as dynamic processes where elements are articulated and rearticulated to make meaning in a relational context. A discussion could be seen as an exchange of meanings in which certain interpretations emerging as significant, Elements are rearticulated and develop significant meaning in relation to each other. Laclau and Mouffe $(2001,105)$ explicate articulations of discourse:

we will call articulations any practice establishing a relation among elements such that their identity is modified as a result of the articulatory practice. The structured totality resulting from the articulatory practice, we will call discourse.

Tokens with certain structuring functions within a discourse are called nodal points. Nodal points are privileged tokens organising related tokens (i.e. moments) in a 'chain of equivalence' (Jørgensen and Phillips 2002).

Elements are those tokens not yet articulated and not crystalised in the particular discourse. They are still in the struggle to make meaning. When the elements are articulated into more fixed meaning they turn into moments of the discourse and thereby the nodal point is given its distinction in the discourse.

Discourse theory is useful in making the re-articulation of ESD discourses visible and possible to problematise (Laclau and Mouffe 2001, Unemar Öst 2009, Bengtsson and Östman 2013). Bringing some of the central concepts of Laclau and Mouffe's (2001) theoretical framework into play, we firstly define Education for Sustainable Development (ESD) as a discourse in articulation. As such, ESD has not an explicit articulation by a particular discourse; instead, there is a struggle between competing discourses trying to make their definition the centre. 


\section{Analyses and results}

The teachers' discussions alternate between different issues. Different definitions, experiences and viewpoints are discussed and in a 'struggle' to make meaning. We start by identifying utterances/elements articulating situations relating to the students' ability to be addressed as political subjects, which could give room for their subjectification. Further, we analyse how those articulations relate to each other and what central 'signifier' (i.e., nodal point) could be distinguished. The study's aim is not to clarify the 'real' meaning of Biesta's functions of education (2009a). It is the process and struggle between different articulations that captures our interest within their particular context. We are interested in how teachers discuss the important aims of ESD, with a special focus on what is articulated about the student's ability to develop as political subject.

This requires a close reading with a reciprocal exchange between transcripts and the analytic framework. To define a nodal point means to define emerging key concepts of the discussion central in formulating the meaning of the particular discourse (Laclau and Mouffe 2001). In the following text, we present results from our analyses showing how the discourse is formulated in opposition to alternative articulations. These results show the relation between the emerging nodal point of critical thinking and its articulated moments (articulations that develop a relational meaning of critical thinking) and struggling elements.

\section{The emerging nodal point: critical thinking}

In the analysis of the discussions, critical thinking emerges as a reccuring ventral theme, articulated as an important part of students' education. However, critical thinking is articulated differently depending on teaching aims. The discourse 'Critical thinking as room for subjectification' is formulated in relation to teachers' articulations of student's ability to develop as political subject. Articulation as: 'Becoming a critical student', 'Promoting reflecting individuals', 'Questioning authority', 'Evaluating sources' and 'Wanting students to develop their own opinions' are examples of elements mutually developing this particular meaning of critical thinking. Meanwhile there are struggling articulations, relating critical thinking to other meanings and purpose of teaching. Examples of those struggling articulations are represented in the following sections: 2 . Struggling articulation of critical thinking: 'Room for subjectification' in relation to qualification and 3. 'Room for subjectification' in relation to socialisation. We analyse these different meanings as trajectories towards different functions of education (Biesta 2009a). This will be developed further in the analyses.

Table 1 illustrates how an element (to become a critical student) gains meaning by articulation of an interlocutor's utterance. This element's meaning is then put in relation to other articulated elements (analysed in the text following the table) and, in this way, it becomes a moment of the discourse. Together, these moments constitute the relational meaning of critical thinking (the nodal point in the discourse). 
Table 1. Example of articulation of an element into moment.

\begin{tabular}{|l|l|}
\hline \multicolumn{2}{|c|}{$\begin{array}{l}\text { Example of articulation of element into moment } \\
\text { Emerging nodal point: critical thinking } \\
\text { The ESD discourse of: critical thinking as room for subjectification }\end{array}$} \\
\hline Teacher's articulation (analysed from transcript) & \multicolumn{1}{|c|}{ Examples of element $\rightarrow$ moment } \\
\hline $\begin{array}{l}\mathbf{1} \text { a) } \\
\text { Johan: From my point of view, I can say [I miss], the } \\
\text { more critical side, that is, they should not just take for } \\
\text { granted all that we say, without questioning...I miss } \\
\text { that critical view. }\end{array}$ & \\
\hline
\end{tabular}

\section{Formulation of the ESD discourse 'critical thinking as room for subjectification'} In the discussions, articulations describing situations that promote critical thinking among the students emerge. Teachers' articulations of critical thinking as room for subjectification are working in tension with articulations of socialisation and aims of qualifications. We start with identifying how teachers' articulations formulate 'critical thinking as room for subjectification' and problematise the struggle with different, overlapping articulations of critical thinking.

1a)

Nodal point Critical thinking

Moment To become a critical student

Articulation Johan: From my point of view, I can say [I miss], the more critical side, that is, they should not just take for granted all that we say, without questioning...I miss that critical view.

In this articulation, 'critical' and 'questioning' are seen as desirable traits, a missing approach of the students. The utterance articulates the importance for students to not accept what the teachers say without reflecting for themselves. This is an example of what could be seen as an articulation of a desirable approach of education that could leave room for the students' subjectification process.

1b)

\section{Nodal point Critical thinking \\ Moment Promoting reflecting individuals}

Articulation Annie: Because it's like this, they [the students] should be reflective individuals, they should for themselves, not just take everything for granted. You [the teachers] have to stress this yourself, that they [the students] feel they can influence, have the desire to influence...

This utterance articulates an initiative to promote a counterbalance to socialisation: '...they should for themselves, not just take everything for granted'. This utterance 
articulates an effort to encourage the students to not simply accept the established order without question. The articulation also relates to empowering the will for action: 'You [the teachers] have to stress this yourself, that they [the students] feel they can influence, have the desire to influence...'

The continuation of this articulation emphasises the possibility of how to use critical thinking as a counterbalance to socialisation (1b):

Annie: I do not think we can cast all [the students] into the same mould, and we shouldn't, that's what we shouldn't do in education...so you have different views on human rights and sustainable development. We notice this when they have discussions, I think it is not a given.

In this part of the articulation, there is a desire to emphasise the importance of revealing different interpretations of the universal concept of human rights. In terms of the students, this could be seen as an awareness that could leave room for the process of subjectification. Another example in line with these articulations is:

1c)

\section{Nodal point Critical thinking \\ Moment Possibilities to question authorities}

Articulation Annie: Usually, I always, with my students [pause]-They say, 'You have taught us that we should always be critical, that we should constantly question'. I have taught them to be critical of me as well. When I teach [I tell them] 'Don't take for granted all that I say. Question!' So my teacher candidate had huge problems when she arrived and started to recite a lot of formulas. They wanted to know the sources: 'Where does this stuff come from? How do we know that this is right?'. You know, to question even authority, because they ought to think for themselves, think critically...

This moment articulates a situation with possibilities to challenge common orders. In this example, the challenge is in questioning the superiority of the teacher who represents 'unquestionable knowledge'.

1d)

\section{Nodal point Critical thinking}

Moment Evaluation of sources

Articulation Irene: Yes, this about evaluation of sources. I have told my students 'Well, what I say today may not be true in twenty years...or even five, ten years'. Things happen after all...but they must have a responsibility to learn for themselves and [pause] not to just believe what people say, but rather, to kind of, investigate...

The first part of this utterance could be seen as articulating different approaches and promoting different aims of education: 'Yes, this about evaluation of sources, I have told my students "Well, what I say today may not be true in twenty years...or even five, ten years". Things happen after all...'. To know that 'facts of today' are not static but under development is a qualification toward understanding how factual knowledge emerges and develops. It is also saying something about how a student ought to think, handle, relate and approach knowledge. It articulates the importance of an understanding to evaluate 
the validity of factual knowledge over time, not to simply take anything as the absolute truth that will remain forever. It allows for an evaluation of what counts as the truth; in other words, it is encouragement for the students to question the guidance of knowledge and not to simply accept established truths without evaluating their validity and relevance.

Furthermore, the latter part of the utterance leaves space for the student to take reflective initiative: '...but they must have a responsibility to learn for themselves and [pause] not to just believe what people say, but rather, to kind of, investigate...'. To question 'what people say' and 'investigate' is a way to make different views of an issue desirable, to encourage the students to investigate and foster awareness. This challenges different perspectives and invites the subjectification processes. The moment's 'evaluation of sources' also articulates possible room for subjectification.

1e)

\section{Nodal point Critical thinking}

Moment Wanting students to develop their own opinions

Articulation Mark: ... when they read something in the newspaper, I always want them [the students] to have a clue what it's all about and draw their own conclusions - that's it, to understand...then, could this really be true?...you really want them to...to develop their own opinions...

This articulation shares the approach of earlier articulations in the meaning of promoting students to critically question the validity and relevance of claims '- that's it, to understand...then, could this really be true?' In addition, the articulation stresses the importance for the students to develop their own position in relation to the applied approach 'you really want them to...to develop their own opinions...'.

Summarising remarks: The ESD discourse of 'Critical thinking as room for subjectification'

Through these articulations of critical thinking (moments 1 a-e), 'room for subjectification' emerges as an important part of this ESD discourse. This discourse articulates critical thinking as a tool to highlight how general discourses can be challenged. The articulations promote an approach of education that gives room for the students to explore their own views in relation to different perspectives, interpretations and values. In this way, the nodal point of critical thinking and the articulated moments develop into particular meaning, opening up the opportunities of the subjectification process. That is, a discourse promoting a reflective approach, listening to alternative interpretations to make a personal exploration without an expected predefined teaching goal as outcome. However, this discourse is challenged by other utterances articulating critical thinking from a slightly different perspective. Therefore, it is in our interest to further analyse relations and tensions in articulations of critical thinking.

\section{Struggling articulations of critical thinking: 'Room for subjectification' in relation to qualification}

At the same time as critical thinking is articulated as the nodal point with a particular meaning in the discourse of room for subjectification, there are elements in the discussion 
that could be identified as opposing articulations. The following utterances are examples of those elements in opposition which develop another significance of critical thinking:

2a)

\section{Nodal point Critical thinking \\ Element Science as a model to be critical}

Articulation Johan: [They need] knowledge that...there is this scientific knowledge about questioning things: 'Why am I doing things the way I do? Why are people doing things the way they do? Actually... why do I eat this? Why do I drink this? Why do I have the clothes that I have?' Instead of 'No, it's probably best that I do like the others-yes'.

Here, scientific knowledge is articulated as a model for questioning and to critically evaluate habits and choices in a qualified way. To make science a model for questioning is a way to promote the nature of science as an investigative procedure, a socialisation into an educational aim.

2b)

\section{Nodal point Critical thinking \\ Element Scientific knowledge as objective truth}

Articulation Lotta: ...I think that the schools' aim is to give students, the scientific part, their understanding of the science behind... and then take a position, after that, because it's very much emotion and other things influencing...

Paul: Yeah...

Lotta: ...especially in the media...to make it correct, we have an important part here...

Henrik: Yeah, I agree

In this articulation, the view of factual knowledge is of interest in relation to earlier articulations of the ESD discourse of room for subjectification. Utterances, like the first by Lotta, highlight the importance of factual knowledge (the aim of qualification) in a way that could be seen as hiding the political. Is this a representation of an approach to turn questions of political character into questions of knowledge? In this articulation, scientific knowledge is seen as an important part of critical thinking, to give us the 'correct' answers as in Lotta's last utterance 'especially in the media...to make it correct, we have an important part here...'. The scientific knowledge is articulated as superior to the other perspectives '... because it's very much emotion and other things influencing...'.

In next example (2c) of struggling elements, knowledge of science is also put forward as a prerequisite to be able to critically interpret and discuss questions of sustainability:

2c)

Nodal point Critical thinking

Element Science as a model to interpret the world

Articulation Nina: ...the proper reasoning [about sustainability] will perhaps not be possible until the B-courses...before you will be able to reflect on something you have to, after all, have a basic understanding...

Irene: Then you know what can be assumed... 
Nina: $M m m \ldots$

Irene: ...somehow, but first they have to have the basic knowledge...

Nina: Yeah, exactly

Irene: He, he...and then it might not be the same type of reasoning.

In this articulation, qualification in a particular subject content (i.e., science) is assumed as a prerequisite before discussing issues of sustainability in a desirable way: '...but first they have to have the basic knowledge'. Without knowledge of science on a certain level (B-course), the discussions do not lead to the desired way of reasoning; for example, to be critically valued through the scientific knowledge which is exemplified by Nina and Irene's utterances '... before you will be able to reflect on something you have to, after all, have a basic understanding...' and 'then you know what can be assumed ...'.

\section{Summarising remarks: Articulations of critical thinking in relation to qualification}

In the articulations above (elements $2 \mathrm{a}-\mathrm{c}$ ), tension is revealed between the meaning of critical thinking in relation to the aims of qualification and room for subjectification. The reasoning is governed into the scientific subject knowledge as prior emotions and political tensions. It articulates a neutral, rational worldview with science as a model to interpret the world. In the context of ESD, this approach could be seen as diminishing the room for subjectification, e.g. students do not have possibilities to explore their ethical and political reasoning in relation to sustainability. Further, there are also competing articulations in relation to the aims of socialisation. We problematise these tensions in the following section.

\section{Struggling articulations of critical thinking: 'Room for subjectification' in relation to socialisation}

When the teachers discuss how students should act as sustainable citizens, the articulations open up room for subjectification, but in slightly different ways. Here, critical thinking is emphasised as a tool to question common established orders.

In the first example of articulation, the socialisation into predefined environmental behaviours is put into question:

3a)

Nodal point Critical thinking

Element Promoting to question what is taken for granted

Articulation Johan: ... and above all, people need more knowledge and scientific literacy... driving force in man, to be like everyone else, it is beyond all imagining...

Rickard: Mmm...

Johan: They are even unconscious in a frightening way...but, to think freely...I think it is the greatest...danger...when suddenly all begins...what should I say? Eat healthy, sort garbage, biking to work or whatever it is...above all, to get used to, again, to think for yourself...uh, more than you're used to...everything you hear, everything you see-is that right? Could it be that way? Like separating waste...ask yourself 'why should I do it?'

This utterance articulates the importance of the students' ability to think for themselves and their ability or possibility to ask the question-Why do I have to recycle? 
To 'think freely' is articulated as important, but emphasised as possible through using knowledge and scientific literacy as the tool for critical thinking '....and above all, people need more knowledge and scientific literacy ...driving force in man, to be like everyone else, it is beyond all imagining...'.

Another example of a perspective on critical thinking in relation to socialisation is articulated by one of the teachers, Mark. He commutes by bike to work, but this is an uncommon practice in the area of the city where the school is situated. By this action, he wants to show that it is possible to not take for granted norms and habits, but to think about alternatives. We define the element in articulation as 'question procedures and actions'.

3b)

\section{Nodal point Critical thinking \\ Element Question procedures and actions}

Articulation Mark: ... what I think is...that sometimes, you can contribute by questioning the obvious [not drive to work but instead go by bike]... a-ha...here is someone not doing as my parents...so, not just going by routine and habits, but to show possibilities to choose what you think is best.

This articulation shows a desire to empower students' possibilities to realise what could be possible through visualising and questioning the norm (commuting by car, in this case). In this way, room for subjectification might be invited.

This utterance articulates how a teacher can act as role model of what could be called sustainable behaviour. By this action, Mark, who functions as an eye-opener for the students, makes them realise that there are other ways to act than the habitual order of behaviour.

\section{Summarising remarks: Articulations of critical thinking in relation to socialisation}

In relation to socialisation, critical thinking is articulated as a competence, enabling students to critically value behaviours, i.e., being able to distinguish the sustainable behaviours from the unsustainable.

The first element (3a) shows how a way to be critical to predetermined ESD discourses might open up for room for subjectification. The second example (3b) articulates how sustainable actions are seen as challenging the taken-for-granted norms of everyday life. Nevertheless, these articulations give rise to further questions of how critical thinking in relation to socialisation is mirrored through the qualification of subject knowledge (i.e. science knowledge) to critically evaluate how to behave as sustainable citizens. We will return to this in the following section 'Conclusions and discussion'.

\section{Conclusions and discussion}

The aim of this study has been to analyse how teachers discuss what they think are the important aims of ESD with a special focus on how the students' ability to develop as political subject (room for subjectification) might be articulated. With inspiration from 
discourse analysis, we analysed the teachers' articulations. The teachers formulated contrasting discourses, with critical thinking as the emerging centre- the nodal point. Critical thinking - articulated as a recurring signifier - may not be a surprising result in itself as it is an important part of a democratic education (Scott and Gough 2003; Öhman 2006; Lundegård and Wickman 2007, 2012; Osberg and Biesta 2010). On the other hand, of particular interest is how critical thinking is articulated as room for subjectification and how critical thinking is reformulated in qualitative meaning in relation to the aims of qualification and socialisation.

\section{Critical thinking in relation to the functions of education}

Recurring articulations of critical thinking are expressed as situations signifying the desire of students' engagement in processes that might open for the subjectification process. The teachers' articulated situations encourage students to develop their own thinking, challenge everyday norms, question authorities and reflect on what is taken for granted. Articulations in this way became organised as a meaningful context in relation to the emerging nodal point of critical thinking, formulating the discourse of critical thinking as room for subjectification.

Critical thinking is articulated as something which occurs in the teaching moment. It is articulated as a way to empower different ways of thinking, including an illumination of taken-for-granted norms which allows them to be questioned and problematised ( $\mathrm{p} 10$, 14). This could create space in the teaching process where students have the possibility to explore their ethical and political perspectives of an issue. In this way, critical thinking might open up possibilities for the subjectification process to take room. In line with Osberg and Biesta (2010), we argue that a created space which makes it possible to think critically in relation to taken-for-granted norms enables a teaching process where students are able to discuss and discover options. Thus, this process is not limited to learning a predefined answer, but rather enables a possible democratic space to be opened up.

it is this continual engagement in judgement (not the arrival at an end point) that makes the educational process educational. (Osberg and Biesta 2010)

As this meaning of critical thinking crystalises, it is also challenged by the function of qualification; the science discourse emerges through the lens of qualification (p 14). Science is superior as a model to view environmental issues through; however, in this contrasting discourse, the rationality is put to the fore and questions connected to the subjectification process as ethical and political issues are seen as hindering objectivity and rational arguments. In this version of critical thinking, the purpose is to scientifically scrutinise arguments and information, i.e., reasoning with arguments built upon scientific knowledge and logical reasoning.

This means that while the teachers' articulate critical thinking as the possibility for students to explore different interpretations and emphasise the complexity and diversity of knowledge perspectives, another epistemology is simultaneously articulated. This is grounded on scientific perspective of a rationalistic worldview. In other words, critical thinking, when analysed through the functions of education, could mean different things 
in an ESD context. This dualism of epistemological perspectives is, in part, a reflection of the different intentions articulated in policy documents and curriculum goals. In the curriculum, one can find goals wherein the students' arguments should lean on scientific reasoning and be grounded in established factual knowledge (National Agency of Education 2011, 2013). In this context, critical thinking is seen as a competence, enabling students to critically value behaviours, i.e., being able to distinguish the sustainable behaviours from the unsustainable. At the same time, ESD is proclaimed as looking to the future, wherein new ways of thinking are emphasised; ESD is articulated from a more postmodern desire to understand and act upon our relationships within the world, focusing on democracy and pluralistic views (Öhman 2006).

Hence, discussions about epistemological views when implementing ESD into the curriculum as an overall perspective are a way to vitalise the education in relation to the challenges of sustainability issues.

In the discussions analysed, the teachers also articulate critical thinking as a way to question both predefined environmentally-friendly discourses and non-environmentallyfriendly discourses. In both cases, critical thinking is articulated as empowering the possibility of an individual to reflect in an alternative way to the common order by discovering other ways of reasoning. The tension between socialisation and subjectification is complex in the way that it works in opposition. The teachers' articulations grasp socialisation as ways of collective behaviour, to be questioned in the educational processes (subjectification). At the same time, this questioning and critical way of thinking is socialisation in itself and in its goal of how educated students should behave. Meanwhile, the way critical thinking is articulated as a way to question behaviour (science as a model) is also revealing as a tool to critically evaluate the ways we are expected behave. In part, the teachers articulate how they themselves can act as role models of sustainable behaviour. By this, they may function as eye-openers for the students, making them realise that there are other ways to act than the habitual orders of behaviour that are seen as unsustainable. This means that the articulation of critical thinking in relation to socialisation in this way might work in line with the qualification function of education with scientific answers as superior, guiding repertoires of sustainability.

\section{Critical thinking in relation to 'room for subjectification'}

To summarise, the articulations in this study formulate an ESD discourse of critical thinking with various qualitative meanings. A consequence of the changes in the use of epistemologies might be that political and ethical issues take the back seat. On the one hand, critical thinking invites room for subjectification. On the other hand, the room for subjectification is challenged when critical thinking is articulated through the educational purpose of qualification and socialisation.

These conclusions should be interpreted in relation to the prerequisites of this empirical study. It reveals how the interlocutors involved in the discussions develop their articulations due to their contextual frame. The articulations reveal the complexity, uncertainty and necessity that characterise questions of sustainability (Scott and Gough 2003; Stevenson 2007; Hasslöf, Malmberg and Ekborg 2014). However, the results also 
reveal how these teachers act in a pragmatic way when reflecting on the purpose of education in the complexity of teaching scientific concepts and relating the complexity of sustainability issues, i.e., to change epistemological views depending on the context.

We realise that critical thinking is a desired teaching concept and equal in importance in relation to all three functions of education; nevertheless, the qualities of critical thinking will have different implications. In this context, it is important to emphasise that what we conclude as a critical approach through room for subjectification is not an 'anything goes' concept, but a desire for students to know more, to investigate and reveal different perspectives.

ESD gives the possibility for education to discuss and open up new and different perspectives regarding our way of living and, by this, to challenge hegemonic discourses. We argue that an important part of ESD is to view our world through a critical eye with room for the subjectification process:

provide opportunities for students to explore their own ways of thinking, doing and being, can be more desirable than those that effectively proceed towards a pre-specified end. (Biesta 2009b, 36)

Educational purpose and goals always combine the relationship between society, institutions and the individual. This relationship is a balancing act. On one hand, there is the question of whether specific curriculum content educates the individual to become a responsible citizen in a defined social order. On the other hand is the individual, who is being offered an education that enables him/her to develop as a political subject and find an identity in a pluralistic and changing world.

\section{Acknowledgements}

We want to thank PhD Iann Lundegård, Stockholm University, for valuable comments in the development of this article.

\section{References}

Bengtsson, S., and L. Östman, 2013. Globalisation and education for sustainable development: emancipation from context and meaning. Environmental Education Research 19, no. 4: 477-498.

Biesta, G. 2009a. Good education in an age of measurement: on the need to reconnect with the question of purpose in education. Educational Assessment, Evaluation and Accountability 21, no. 1: 33-46

Biesta, G. 2009b. On the Weakness of Education. Philosophy of Education Yearbook: 354-362.

Biesta, G.J.J. 2010. Good Education in an Age of Measurement-Ethics, Politic, Democracy. Boulder, Colorado: Paradigm Publishers. 
Hasslöf, H., M. Ekborg and C. Malmberg. 2014. Discussing Sustainable Development among Teachers: An Analysis from a Conflict Perspective. International Journal of Environmental and Science Education 9, no. 1: 41-57

Jickling, B. 2003. Environmental education and environmental advocacy: Revisited. The Journal of Environmental Education 34, no. 2: 20-27.

Jickling, B., and A.E.J. Wals. 2008. Globalization and environmental education: Looking beyond sustainable development. Journal of Curriculum Studies 40, no. 1: 1-21.

Jørgensen, M. W. and L.J. Phillips. 2002. Discourse Analysis as Theory and Method. SAGE Publications Ltd. London

Laclau, E., and C, Mouffe. 2001. Hegemony and socialist strategy: Towards a radical democratic politics. 2nd ed. London: Verso.

Læssøe, J. 2010. Education for sustainable development, participation and socio-cultural change. Environmental Education Research 16, no. 1: 39-58.

Leo, U., and P. Wickenberg.2013. Professional Norms in School Leadership: Change Efforts in Implementation of Education for Sustainable Development. Journal of Educational Change 14, no. 4: 403-422.

Lundegård, I., and P.O. Wickman. 2007. Conflicts of interest: an indispensable element of education for sustainable development. Environmental Education Research 13, no. 1: $1-15$.

Lundegård, I., and P.O. Wickman. 2012. It takes two to tango: studying how students constitute political subjects in discourses on sustainable development. Environmental Education Research 18, no. 2: 153-169.

Mouffe, C. 2000. Deliberative Democracy or Agonistic Pluralism. Political Science Series 72. Institute for Advanced studies, Vienna.

National Agency for Education. 2011. Curriculum for the compulsory school, preschool class and the leisure-time centre. Lgr 2011. Stockholm. Retrieved 20/12/2012 from http://www.skolverket.se/publikationer?id=2687

National Agency for Education. 2013. Curriculum for the upper secondary school. Stockholm. Retrieved 10/05/2014 from http://www.skolverket.se/publikationer?id=2975

Öhman, J. 2006. Pluralism and criticism in environmental education and education for sustainable development: A practical understanding. Environmental Education Research 12, no. 2: 149-63.

Osberg, D., and G. Biesta, G. 2010. The end/s of education: complexity and the conundrum of the inclusive educational curriculum. International Journal of Inclusive Education 14, no. 6: 593-607.

Rudsberg, K., and J. Öhman. 2010. Pluralism in practice: Experiences from Swedish evaluation, school development and research. Environmental Education Research 16, no. 1: 95-111.

Scott, W., and S. Gough. 2003. Sustainable development and learning: Framing the issues. London: Routledge Falmer.

Stevenson, R.B. 2007. Schooling and environmental education: contradictions in purpose and practice, Environmental Education Research 13, no. 2: 139-153.

Unemar Öst, I. 2009. Kampen om den högre utbildningens syften och mål. En studie av svensk utbildningspolitik. [The struggle of defining the purposes and aims of 
higher education. A study of education policy in Sweden.] PhD diss., Örebro Studies in Education 27, 268 pp.

United Nations Educational, Scientific and Cultural Organization [UNESCO]. 2006. Framework for the UNDESD international implementation scheme. UNESCO education sector.

United Nations Educational, Scientific and Cultural Organization [UNESCO]. 2012. Retrieved 20/12/2012 from http://www.unesco.org/new/en/education/themes/leadingthe-international-agenda/education-for-sustainable-development

Wals, A. 2009. Review of Contexts and Structures for Education for Sustainable Development. Learning for a sustainable world. UNESCO. Paris.

Winter, P. 2011. Coming Into the World, Uniqueness, and the Beautiful Risk of Education: An Interview with Gert Biesta by Philip Winter. Studies in Philosophy and Education 30, no. 5: 537-542. 